\title{
The Socratic Lecture Model: An Effective Teaching Pedagogy in Changing Educational Scenario
}

\author{
Akhilesh Arvind Nimje ${ }^{1}$, Kalyani Tripathi Dubey ${ }^{2}$ \\ Associate Professor, Department of Electrical Engineering Guru Nanak Institute of Engineering and \\ Technology Nagpur, INDIA \\ Assistant Professor, Department of Applied Sciences and Humanities Guru Nanak Institute of Engineering and \\ Management Nagpur, INDIA
}

\begin{abstract}
This paper presents Socratic Method of teaching as an essential tool to improve teaching learning process. The results presented in this paper are obtained by blending conventional and Socratic Method of teaching to allow smooth transition in teaching method. It shows improvement in various parameters such as average attendance, assignment submission, marks obtained, learner's ability and student's feedback.
\end{abstract}

Keywords: Socratic, pedagogy, interactive classroom, moral education.

\section{INTRODUCTION}

In the era of changing educational scenario, teachers are expected to perform differently. There is pressure from every corner to bring in reforms. Over the past 20 years, there has been increased competition, access to internet, search engines, social networking websites, electronic gadget and changing lifestyle. The information is available at a click away. This is time to realize that the students no longer have to depend upon teachers for acquiring knowledge and therefore professors report poor attendance in class. The teacher's role has become even more challenging and difficult. This necessitates the development of new and innovative teaching pedagogies. With this in view, several changes in education system has been brought in terms of increased coverage, better infrastructure, open education resources, inclusion of cross cutting themes in curricula, implementation of measurement parameters for achievement of quality assessment, management of education systems etc. Yet, the problems like syllabus coverage, emphasis on memorizing certain paragraphs from book and evaluation on the basis of reproduction of texts from book persist. The university education needs bridging gap between industry and academia. Students spend three to four years acquiring various analytical and reasoning skills and the moment when they pass out, the entire market changes expecting different skills. In addition to this, there is lack of personality development lesson, lacking moral and ethical teaching, lacking lessons to become an individual beyond religion, region and barrier of language. It also does not emphasize on patriotism, humanity, creativity, heritage and culture. The students are unaware of the purpose for which they are studying a particular subject. The evaluation and assessment has become lenient degrading the quality of education. The inconsistent education has been a major concern. The present education from kindergarten to post graduate has become very costly beyond the common man's reach especially for rural people. Most of the educational institutions are running successfully because they make the students ready to be placed directly into the work force. The graduates from most of the schools/ universities are unemployable because of poor course material and teaching quality. To our mind, present education system is not playing its significant role in shaping the future of youth but makes students corrupt and teaches them only hungriness for indulgence, self centeredness, power and money. It gives degrees/ diploma without fundamental knowledge and prepares them for a job at the cost of their overall development. The major responsibility for student's transformation therefore lies with the teacher's stride. The teachers need to explore various opportunities to go beyond the conventional teaching practices and develop innovative teaching models [1]. This may help the learners to imbibe higher levels of understanding and effectively apply concepts learnt to varying practical situations. This calls for redefining the current education system to achieve the professional goal. It needs to analyze the professional task of teachers such as teaching, educating, counseling, evaluating, administrating and innovating. The focus is on study and design of conducive learning environment compatible with students to learn effectively. Since teaching is an interactive process, if a teacher stops making any effort to improve, probably, it is time to retire. Teaching is often considered to be delivering lectures for 60 minutes, perhaps ask few questions that are answered by few assertive students in the front rows. This kind of teaching enables the students to take notes in less time and more time testing their understanding of content. Such a teaching strategy does not guarantee that students learnt everything during lecture or learning at home. The teaching philosophy that may work in one situation may not work for all and therefore it is individual and site specific. The best way to teach is to pose questions and ignite students to think innovatively to arrive at the desired answer. The flow of discussion 
continues through forward questioning. Such a teaching method is termed as 'Socratic Lecture Model'. The teachers thus ask questions in an effort to expose the values and beliefs which frame and support the thoughts and statements of the participants in the inquiry. The process of questioning can be either one way or two ways. The inquiry progresses interactively and the teacher is as much a participant as guide of the discussion engaging students with critical thinking process [2]. The students should be made aware of what is new in an interactive classroom and how does it differ from traditional lecture? What levels of understanding is improved when they are asked to change from passive note taking mode to active participation? And how does a teacher develop high impact teaching skills?

\section{Interactive Classroom}

\section{II . ATTRIBUTES OF SOCRATIC LECTURE MODEL}

An interactive classroom intellectually engages the students as active participant with teacher as an engagement trigger that captures and maintain student's attention. The teacher allows the students to apply what they have learnt and give them a context for upcoming lecture material. The teacher feels enriched with student's participation and thinks upon the blend of interactive techniques for next class.

\section{Time Management}

The syllabus coverage is given the utmost importance in most of the schools and universities. This needs time bound completion of several academic activities. Lecturing is a time honored activity which can be effectively accomplished using Socratic lecture model to deliver large content within optimum time frame.

\section{Teacher is not Devil's Advocate}

"If you affirm it, I deny it. If you deny it, I affirm it." The Socratic Professor is not an opponent in an argument. The teacher plays more than a teacher's role such as friend, guide, facilitator, guardian and role model. In fully residential schools/ universities, the teacher has many other roles to play. He asks questions not only to test the students but helps him/ her to arrive at meaningful answer.

\section{Students Participation}

The teachers are encouraged not to teach the content but to teach the students how to learn. Because learning is a process of actively exploring information and validating with previously acquired knowledge and experience and creating new knowledge or reevaluating existing knowledge. Socratic method substitutes self directed learning opportunities instead of classical lecturing practices.

\section{Feeds Students with Endless Content}

Sometimes, deep questioning drives the thought underneath the surface of things force students to deal with complexity. The questions on interpretation help to examine and organize meaningful information while the questions on assumptions help to examine what is taken for granted. The questions on implications examine the orientation of discussion.

\section{Provides Essential Tools}

The conventional lecturing is very common teaching tool to use for all classroom situations. If on the other hand, if you have several tools in your toolbox, you will have the opportunity to pick up the most appropriate tool for the task at hand. The Socratic Method clearly defines the learning objectives and gives students ample opportunity to practice new learning skills. The well crafted questions act as tool to generate a more sophisticated and self directed learning. The students are trained to become independent of the teacher, who models how to ask appropriate questions. An effective teacher gives students the tools requisite to formulate their own ideas and thoughts. Teachers are supposed to inspire their students, giving them academic wings.

\section{Focus on Moral Education}

A good teacher forms strong relationship with his/ her students and show that he/ she cares about students as individual. The substance of Socratic enquiry is the belief and value the participants. The Professor is a participant in dialogue and is always open to learn something new and does not seek difference to his/ her authority.

\section{Clear Objective}

\section{Socratic Lecture Planning}

The development of basic skill among students is the prerequisite to understand the complex subject. Most universities claim to impart quality education through regular syllabus alterations to a small extent. A 
Professor in Electrical Engineering should never skip teaching Ohm's Law before teaching Electrical Network Analysis. It is possible to convey significant amount of content and utilize time for other activities such as web searching, using indexes, reading and critiquing the scientific literature, data analysis and interpretation. The discussion of non-content material in classroom helps to design multiple classroom activities.

\section{Identify Essential Content}

While teaching load flow analysis in Electrical Engineering, it is important to explore where and how is it used for power flow management. It is essentially relevant to correlate the text book content with State Load Dispatch Centre and Power Grid Corporation of India Limited though it is not mentioned in the university syllabus. This gives the feel of having studied the power network effectively among the students. The key ingredient is that the students had to understand the basic concept and not simply memorize the equations based on numerical recipe.

\section{Decide on Content Quantity}

The generation of students that we are teaching now has grown up with computers. The teachers may ask students to read and come prepared for next lecture so that a substantial knowledge base is created by themselves which needs to be supported by advanced topics delivered by the teacher. On the contrary, only front benchers will read and others will nod their heads pretending that they have read. To bridge the gap between the student's intellectual capabilities among these categories, the one who has already studied the content may be asked to summarize what he has understood. This may cut short the content to be delivered.

\section{Content Organization}

Set down the conversational guidelines. Ask questions and be comfortable with silence. The home work to be done on certain strategies encourages higher student's engagement and individual participation. In what ways do sentence frame helps students learn to respectfully express ideas. And above all, how to use Socratic Method with the teaching content. The teacher has to be attentive in making sure that everyone speaks at some point. The content organization should be such that the learning objectives are clear with mutual understanding rather than a soft debate or making of arguments.

\section{Frequently Notifying the Purpose}

Most of the students at present age are unaware of the purpose of studying a particular subject. They read it, memorize, write exams and forget. The prime cause of such study nature is they do not understand the practical application of a theory, a mathematical equation or a schematic diagram. It is therefore, instructor's duty to explain the purpose of studying the subject. For example, the students of archeology should be aware that it is a scientific study of non renewable and often fragile material remains of past human activity. Archeologists excavate on land and under water to recover the evidences that reconstruct and describe bygone cultures, technology and behavior. They also try to explain how populations adapted to, or were changed by, different natural environments or social circumstances. Archeology reinforces the concept of a shared human heritage and provides modern people with perspective on their own place and time in history.

\section{Assessment of Teaching Style}

The students often describe Socratic Method as engaged learning. The qualitative assessment of teaching method can be assessed by presentation, discussion, tutorial, project supervision, demonstration, field work, external visits, work based learning, independent study, examinations, academic results, placements and feedback from employers.

\section{IV . TEACHER's ROLE}

The way students act largely depends upon the teacher's attitude. The teacher's should feel proud, blessed and love their profession in order to convey enthusiasm, assist and provide warm and protective environment to the students. There are variety of students in classroom between the range of slow learners and fast learners. Few of them feel shy or inferior to participate in forward questioning process due to lack of communication skill. If the students feel good about the teacher, the outcome is evident in the results. The very first day, when teacher interacts with students must have a formal or informal introduction followed by knowing names of each student. This is a good exercise to do because it benefits the whole class to break the ice. Learn with fun is very effective because students feel attracted towards an exciting lesson. "Accept the person (student) as he or she is" should be the Gurumantra of a teacher. The teachers need to understand that different students bring different traditions and customs because they are from different region, religion and speak different languages. The teachers-students need to build a strong bond by showing mutual respect and trust. Most of the reforms and changes proposed by educationists recognize the fundamental role of teachers. This 
statement in itself shows progress, in contrast to other times during which the emphasis was on curricula, administration, norms, infrastructure and textbooks [6].

\section{Case Study}

An experimental study was conducted on 40 Electrical Engineering students to assess the effectiveness of blending Traditional and Socratic Lectures in KIIT University, Bhubaneswar, India. The method of teaching was blended to allow smooth transition from conventional method to scientific approach. The purpose of this study was to involve students through brainstorming, group discussion, googling and forward questioning. The preparation time for each lecture was three to four hours including making notes, planning for sequence of delivery of instructions and searching for relevant audio video clips representing the recent trends and development in the practical field. There were some challenges in its implementation such as non participation of back row students at the initial stage but as we moved along, it grabbed the attention of everyone and the rest of the session went with a lot of interaction and positive energy. The students were listening, interacting and focusing their attention completely to reveal the facts about each topic and audio visual clips shown to them. At the end each class, students were asking very interesting questions and it was observed that they have curiosity to learn more. A short quiz test was conducted at the end of the week and it was seen that student's performance had improved.

\section{Results}

The results of the experiment are surprising, especially when compared with traditional teaching mehod. The test results are optimistic when conducted followed by the topic discussion. Perhaps the benefits of such teaching may differ when compared with long term memory.

\begin{tabular}{|l|l|l|}
\hline Parameter & $\underline{\text { Traditional }}$ & $\frac{\underline{\text { Traditional and }}}{\text { Socratic Method }}$ \\
\hline Average Attendance & $60.43 \%$ & $77.70 \%$ \\
\hline Assignment Submission & $90 \%$ & $100 \%$ \\
\hline Average Marks out of 40 & 27.30 & 30.80 \\
\hline Learner's Ability about & Non participative & Improved \\
\hline $\begin{array}{l}\text { Student's feedback out of 5 } \\
\text { Teacher's attitude }\end{array}$ & 4.38 out of 5 \\
\hline
\end{tabular}

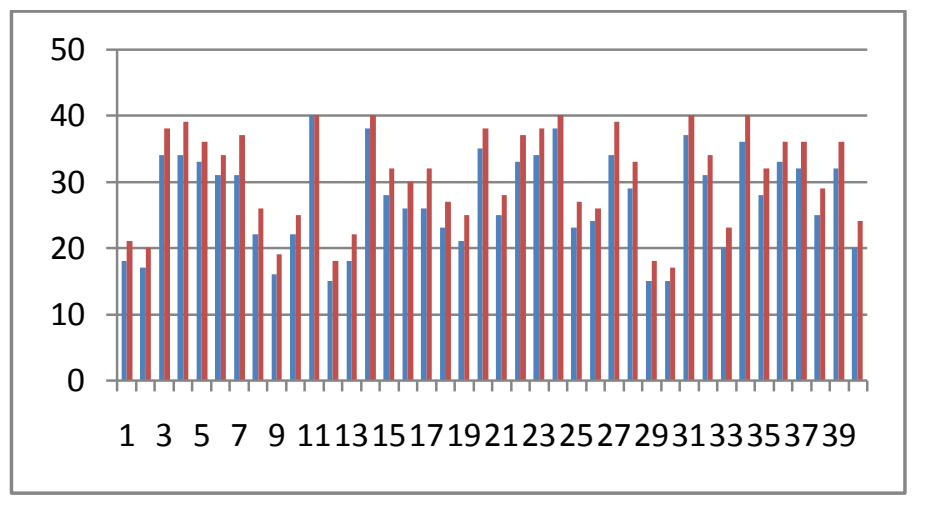

Fig. 1 Marks out of 40

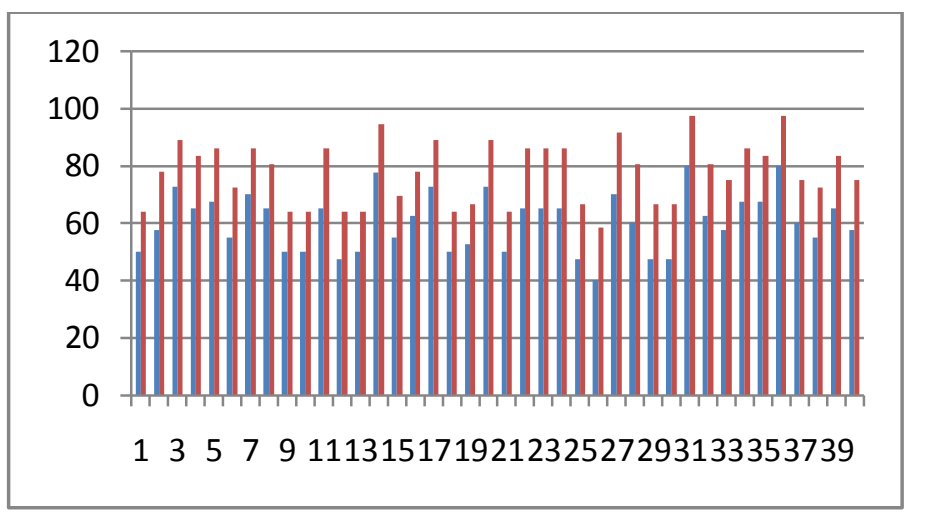

Fig. 2 Improvement in Percentage Attendance of 40 Students 


\section{Students Feedback}

The student's feedback was collected from 40 students based on professional competence and personal attributes of teacher. There were fifteen numbers of questions in feedback form and all students participated in feedback process. It was collected by another teacher from the university to ensure fairness in feedback.

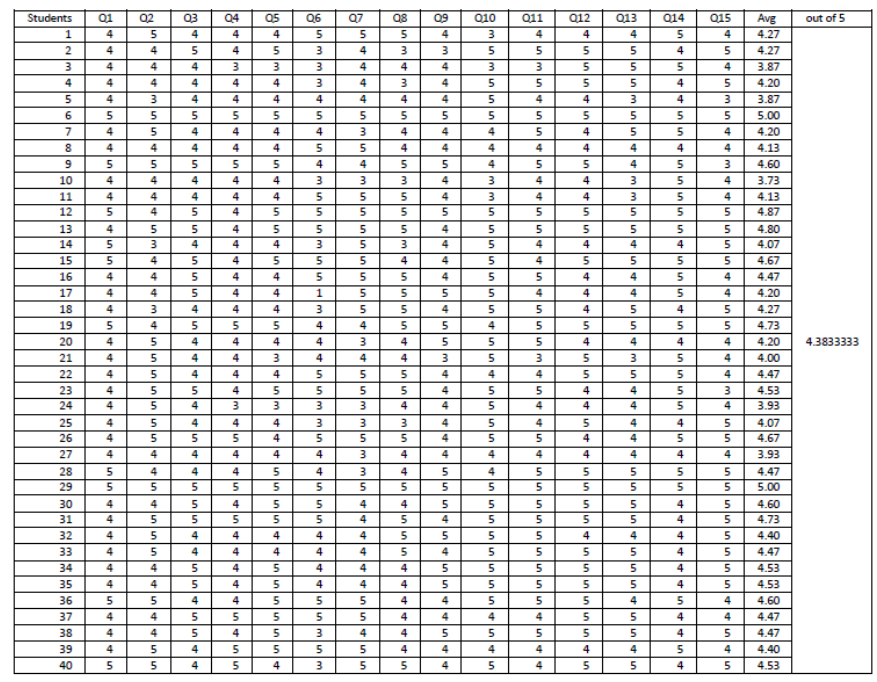

\section{Discussion}

Test intervals and different test times may affect the student's performance. The results obtained in this study may not be generalized for every lecture or subject. It would take elongated transition from conventional teaching method to scientific approach in teaching because traditional lectures are still the most popular instructional method in the universities. The results of case study show very optimistic nature due to limited number of lectures (4 hours in a week). It was also found that the students who perform outstanding with traditional method also perform similar in scientific (Socratic in this case) method. But this method benefits more to slow learner students.

\section{Conclusion}

Both approaches, the Traditional and Socratic teaching are effective in increasing the knowledge of students. The study on Socratic Method of teaching reveals the fact that students (technical or non technical) show active participation in teaching learning process [4]. All the students expected to be questioned when Socratic Method was implemented. It was also concluded that students perform somewhat different when examined using unique sample of questions. The teachers need to act as facilitator and should ensure the availability of resources and opportunities for practice. Furthermore, studies may be needed to explore specific approach on teaching learning pedagogy and long term knowledge sustainability of Socratic method.

\section{References}

[1] A. H. Premji, "In Persuit of Excellence in Engineering Education Through Innovation", Wipro's Mission 10X, 2007.

[2] Rob Reich, "The Socratic Method: What is it and How to use it in the Classroom", Speaking of Teaching, Stanford University Newsletter on Teaching, FALL 2003, Vol 13, No.1, May 2003.

[3] D. U. Silverthorn, "Teaching and Learning in the Interactive Classroom", Advances in Physiology Education, December 2006.

[4] Mohsen Adib Hajbaghery, Mohammad Aghajani, "Traditional Lecture, Socratic Method and Student Lectures: Which One do the Students Prefer?" WebmedCentral MEDICAL EDUCATION 2011; 2(3): WMC001746, March 2011.

[5] Andreja Lavric, "Teachers' Reflections on Their Attitude Towards Students", Association of Teacher Education in Europe, $31^{\text {st }}$ Annual ATEE Conference, October 2006.

[6] "Teacher Involvement in Educational Change", PRELAC Journal, Regional Educational Project for Latin America and The Caribbean, July 2005.

[7] Bonni Gourneau, "Five Attitudes of Effective Teachers: Implications for Teacher Training", University of North Dakota. www.usca.edu/essays/vol132005/gourneau.pdf

[8] Affizal Ahmed, Rafidah Sahak, "Teacher- Student Attachment and Teachers' Attitude Towards Work", Jurnal Pendidik Dan Pendidikan, Jil. 24, $55-72,2009$.

[9] Jennifer M. Cassady, "Teachers' Attitude Towards the Inclusion of Students with Autism and Emotional Behavioral Disorder", Electronic Journal for Inclusive Education, Vol. 2, No. 7, winter 2011. 